effect on the vaso-motor centre. Withdrawal of cerebrospinal fluid tends to lower the blood pressure, but the net result of lumbar puncture is to raise it for at least 20 minutes afterwards. The blood pressure variations in high and low spinal anæesthesia are also described and discussed. 6. Edema of the Orbital Tissues, by John Hill Abram. Two cases are described, one of which was due to actinomycosis. 7. Romarks on Syphilitic Pseudo-tabes, with the Record of a Case, by W. B. Warrington. The case presented symptoms strongly suggesting tabes as the diagnosis, but pathologically the lesions were widely spread meningitis and vascular disease, both due to syphilis. Other cases of similar character are on record, and the possibility that syphilitic lesions may cause symptoms very like those of tabes is recognised, hence the name syphilitic pseudo-tabes. The distinctive characters from the points of view of diagnosis and treatment are discussed. 8. Sinus Arrhythmia of High Grade induced by Digitalin, by E. E. Laslett. Three cases are described, and tracings are given and dis cussed. 9. Auricular Fibrillation Associated with a High Degree of A.-V. Block and Paroxysmal Tachycardia, by C. E. Lea. A case is recorded which ended fatally. Tracings are given and their significance is analysed. 10. Congenital Osclusion of the Duodenum, by E. Marshall Cowell. A brief historical account of the condition is given, a case is carefully recorded, and an analysis of recorded cases with a bibliography is appended.

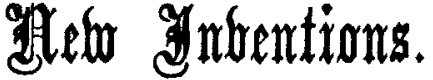

\section{THERMOS SALINE INFUSION APPARATUS.}

THIs apparatus consists of a vacunm flask, a syphon, a water gauge, and a two-way tap. The vacuum flask is of the ordinary thermos pattern and holds either one or two pints. The syphon has two limbs, one a rubber tube reaching to the bottom of the flask, the other of plated copper, reaching down outside to a point below the flask and terminating in the tap. Parallel with the syphon tube and connected with its lower end above the tap is a water gauge of glass tube protected by a metal guard. This gange carries above a rubber ball used for filling the syphon. The flask stands upright in a small tray and may easily be detached. It is closed by a cap which may be removed for

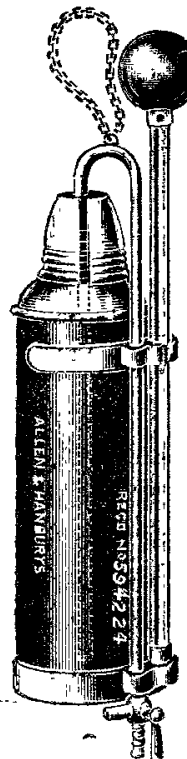
re-filling without disturbing the syphon. The method of use is as follows. The flask is filled with hot saline, the syphon, \&c., being already attached. The tap is closed. The rubber ball is compressed, a small hole below it is closed by the finger, and the ball is released. A rush of flaid follows ronnd the syphon and up the gauge and the apparatus is ready for use. The flask is hung by means of the chain from any convenient support above the patient's bed and the needles for subcutaneous infusion or the rectal tube are connected by rubber tube with a nozzle below the tap. The rate of flow is regulated by the tap and observed on the gauge. Shuuld it be desired to discontinue the flow for a snort time the tap is closed and before re-starting the syphon is emptied of its now cold contents by the side nozzle on the two-way tap. The temperature at which the saline should be poured into the flask will, of course, depend upon the rate of flow, the length of tabe exposed, and the temperature of delivery required. It is found that if the saline in the flask is at $125^{\circ} \mathrm{F}$., the rate of flow one pint per hour and one foot of rubber tube is exposed, the temperature of delivery is about $105^{\circ}$ in a room at 600 . At a rate of half a pint per hour, the initial temperature should be $130^{\circ}$. These figures are only approximate, but are sufficiently accurate for all practical purposes. The temperature of the saline in the flask is almost constant, falling about $1^{\circ}$ per hour.
If, then, the flow remains constant the temperature of delivery will be unaltered so long as the apparatus is not disturbed. For subcutaneous infusion it is essential that the apparatus should be sterilised. This is readily accomplished by filling the flask with boiling water and running this out through the tubes in the ordinary way. The needles should be separately boiled.

The advantages of this apparatus are its extreme simplicity, both in construction and action, its absolute reliability, and the fact that it can be readily sterilised. The flask being upright there is no risk of leakage and no danger of breaking the glass lining by inserting a stopper. The whole apparatus can be in action within five minutes of the moment when it is requested and it requires no further attention. A remarkable feature is the large quantity of saline absorbed by this method. 0 wing to its constant high temperature it is taken up at once into the vessels, there is rarely any swelling of the legs or return by rectum, shock is successfally combated, and renal excretion is increased. At the London Hospital we constantly give five pints subcutaneously by this method in as many hours, and occasionally twice that amount, with no result whatever other than a very remarkable improvement in the patient's condition. In critical cases we use temperatures higher than those mentioned with striking success. Any excess of flaid given is at once balanced by its rapid excretion-in marked contrast to the water-logged subcutaneous tissues so often resulting from the older methods where the temperature of delivery too often was merely that of the atmosphere.

The apparatus has been constructed to my design by Messrs. Allen and Hanburys, of Wigmore-street, London, W. Devonshire-place, $\mathbf{W}$. H. S. SOUTTAR, F.R.C.S. Eng.

\section{NASAL DILATING OLIP.}

THE small clip here figured I have found useful when treating pneumonia, as well as in other cases in which a

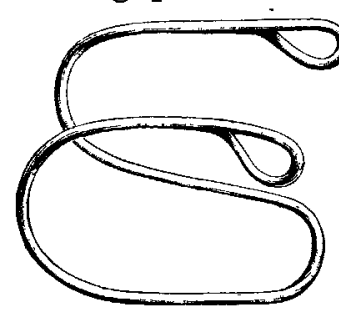
free entry of air is necessary. It saves all the laborious working of the levator alæ nasi muscles. It would also be of service during the administration of an anæsthetic when the nostril is small. The two small loops are inserted into the nostrils and gently worked into position, the bend adjusts itself over the tip of the nose, and remains in place.

The instrument, which is simple and inexpensive, can be made in various sizes. The makers are Messrs. S. Maw and Sons, Aldersgate-street, London, E.C.

Pinxton.

H. J. L. BULLEN, M.R.O.S. Eng.

The Third International Medical Congress OF LABOUR ACCIDENTS.-The Third International Medical Congress of Labour Accidents will be held in Düsseldorf from Angust 6 th to $10 \mathrm{th}$. As the Great Exhibition of Cities there will then be open the members will have the opportunity of inspecting also its medical section, in which will be given a display of matters relating to modern hospital organisation and the special services for the victims of labour accidents. The report of the investigation decided on at the last congress, held in Rome, will be submitted, and the following subjects will also receive attention:-The comparative state of the Oompensation Acts in force in different countries, and the subject of insurance against occupational diseases; the importance of early functional treatment; vascular diseases and accidents ; arthritis deformans and accidents ; influence of accidents on cancerous diseases; the examination of injured persons, especially in respect of measurements, the formation of callnsities, and the comparison between righthanded and left-handed persons. Traumatic neuroses and hernias will be excluded. Questions relating to eye and ear diseases, except in so far as they may be included under one of the preceding headings, will be discussed separately on the last day of the Congress. The secretary-general is Professor Dr. Siniger, Landeshaus, Düsseldorf. There will be the usual receptions and excursions and a banquet on the 8 th, to which ladies will be admitted. The membership fee is 20 marks (£1) 